\title{
Overexpression of KAI1/CD82 suppresses in vitro cell growth, migration, invasion and xenograft growth in oral cancer
}

\author{
JUAN CHAI $^{1,2^{*}}$, LIANGZHI DU ${ }^{3 *}$, JUN JU $^{2}$, CHAO MA $^{2}$, ZHIYUAN SHEN ${ }^{2}$, \\ XIANGMING YANG ${ }^{2}$, LIANG LIANG ${ }^{2}$, QIANWEI NI ${ }^{2}$ and MOYI SUN ${ }^{2}$ \\ ${ }^{1}$ Department of Oral and Maxillofacial Surgery, School of Stomatology, Xi'an Medical University, Xi'an, Shaanxi 710021;
${ }^{2}$ State Key Laboratory of Military Stomatology, Department of Oral and Maxillofacial Surgery, School of Stomatology,
The Fourth Military Medical University, Xi'an, Shaanxi 710032; ${ }^{3}$ Clinical Research Center of Shaanxi Province for Dental
and Maxillofacial Diseases, College of Stomatology, Xi'an Jiaotong University, Xi'an, Shaanxi 710004, P.R. China
}

Received December 14, 2015; Accepted December 6, 2016

DOI: $10.3892 / \mathrm{mmr} .2017 .6186$

\begin{abstract}
KAI1/CD82 is a metastatic suppressor gene in human prostate cancer and several other types of cancer in humans. The present study aimed to examine the role of the overexpression of KAI1 in the progression of oral cancer. Human KAI1/CD82 cDNA was transfected into OSCC-15 and 293T cell lines, and its effects on OSCC-15 cell proliferation, invasion and apoptosis were assessed by performing a 3-(4, 5-dimethylthiazol-2-yl)-2, 5-diphenyltetrazolium bromide assay, Matrigel invasion and Annexin V-FITC staining, respectively. In addition, a xenograft model was used to assess the effect of KAI1/CD82 on the in vivo growth of tumors. The overexpression of KAI1/CD82 inhibited the proliferation and invasion of OSCC-15 cells. It also enhanced the apoptotic rate of the OSCC-15 cells. Furthermore, the overexpression of KAI1/CD82 inhibited tumor growth in the xenograft model. The results demonstrated that the overexpression of KAI1/CD82 significantly inhibited the proliferation and invasion of human oral cancer cells, and inhibited tumor growth in the xenograft model. Therefore, KAI1/CD82 may be considered as a potential therapeutic target in oral cancer.
\end{abstract}

Correspondence to: Dr Moyi Sun, State Key Laboratory of Military Stomatology, Department of Oral and Maxillofacial Surgery, School of Stomatology, The Fourth Military Medical University, 145 West Changle Road, Xi'an, Shaanxi 710032, P.R. China

E-mail:moyisun@163.com

Dr Juan Chai, Department of Oral and Maxillofacial Surgery, School of Stomatology, Xi'an Medical University, 1 Xin Wang Road, Xi'an, Shaanxi 710021, P.R. China

E-mail: chaijuan82@126.com

${ }^{*}$ Contributed equally

Key words: KAI1/CD82, oral squamous cell carcinoma, cancer, xenograft

\section{Introduction}

Head and neck cancer (HNC) is the sixth most common type of cancer in humans; it can develop in any of the following organs: Lips, oral cavity (mouth), nasal cavity (inside the nose), paranasal sinuses, pharynx and larynx. An estimated 300,400 new cases of oral cavity cancer, and 145,400 cases of oral cavity cancer-associated mortality occurred worldwide in 2012 (1). In cases of HNC, 90\% develop head and neck squamous cell carcinoma (HNSCC), which is the leading cause of HNC worldwide (2). The development of HNSCC has been associated with certain environmental and lifestyle risk factors, including alcohol consumption, tobacco smoking, UV light exposure, use of chemicals and viral infection (3). Furthermore, when patients develop this disease, they also experience maxillofacial deformity and psychological changes in addition to the common symptoms of cancer. As with other types of cancer, the development of HNSCC is also associated with multiple genetic alterations, including the overexpression of certain oncogenes and the reduced expression of tumor suppressor genes $(4,5)$.

KAI1, which is also known as CD82, and antigens R2, C33, IA4 and 4F9, are members of the tetraspanin family of proteins. KAI1 is located in chromosome 11p11.2, and it encodes 267 amino acids with the transmembrane proteins in eukaryotes $(6,7)$. Its expression was first identified during T-cell activation (8). Later, it was found to elicit the suppression of prostate cancer metastasis using a somatic cell hybridization technique (9). Previous studies have also reported that the expression of KAI1 is correlated with the progression of several types of human cancer. It has been categorized as a metastatic suppressor in various types of human cancer, including cancer of the prostate $(10,11)$, bladder $(12,13)$, breast $(14,15)$, colon $(16,17)$, pancreas $(18)$ and lungs $(19,20)$. Previous studies have also reported that there is a significant association between downregulated expression of KAI1 and primary oral tumors, which are associated with lymph nodes (21-23). However, there have been no reports on the outcome of the overexpression of KAI1 in oral cancer. Therefore, the present study aimed to investigate the role of KAI1 in oral cancer by transfecting its full-length cDNA into malignant oral cancer cells. 


\section{Materials and methods}

Isolation and cloning of KAII cDNA. The complete DNA sequence of KAIl was amplified from the human brain cDNA library using the polymerase chain reaction protocol (6). The primers used for KAI1 amplification were as follows: Forward 5'-ATGGGCTCAGCCTGTATCAAAG-3' and reverse 3'-GTA CTTGGGGACCTTGCTGTA-5'. Following amplification, the KAI1 cDNA was digested with EcoRI and SalI restriction enzymes (BLKW Biotechnology, Beijing, China). It was then ligated with the pIRES2-EGFP vector overnight at $16^{\circ} \mathrm{C}$. Thus, the recombinant plasmid, pIRES2-EGFP-KAI1 was constructed. This plasmid was then purified using a QIAGEN Plasmid Purification kit (cat. no. 12125; Qiagen, Inc., Valencia, CA, USA).

Cell culture, transfection and selection. 293T and OSCC-15 cells were purchased from American Type Culture Collection (Manassas, VA, USA). These cells were cultured in Dulbecco's modified Eagle's medium (Sigma-Aldrich, Merck Millipore, Darmstadt, Germany), which was supplemented with $10 \%$ fetal bovine serum (Invitrogen; Thermo Fisher Scientific, Inc., Waltham, MA, USA). The cell culture was incubated at $37^{\circ} \mathrm{C}$ in a humidified atmosphere containing $5 \% \mathrm{CO}_{2}$. The cultured cells were passaged every 2 days and fresh medium was added to the culture.

The 293T cells were transfected with the pIRES2-EGFPKAI1 plasmid in a low serum culture medium (Opti-MEM; Gibco; Thermo Fisher Scientific, Inc.) using Lipofectamine ${ }^{\mathrm{TM}}$ 2000 transfection reagent (Invitrogen; Thermo Fisher Scientific, Inc.), according to the manufacturer's protocol, at room temperature. Following transfection, $90 \%$ confluent cells were cultured in a $\mathrm{CO}_{2}$ incubator at $37^{\circ} \mathrm{C}$. After 24 , 48 and $72 \mathrm{~h}$ of transfection, the expression of KAI1 was evaluated in the $293 \mathrm{~T}$ cells using western blot analysis. This plasmid and the pIRES2-EGFP vector were transfected into the OSCC-15 cells. At $24 \mathrm{~h}$ post-transfection, the cells were washed with phosphate-buffered saline (PBS) and placed in fresh medium containing $600 \mathrm{mg} / \mathrm{ml} \mathrm{G} 418$ antibiotics (Invivogen; Thermo Fisher Scientific, Inc.). The cells were grown for 7-10 days (24) at $37^{\circ} \mathrm{C}$. Subsequently, stable clones expressing KAI1 were selected via GFP detection. Fluorescence was examined under a fluorescence microscope (BX51-32FB3F01; Olympus Corporation, Tokyo, Japan) For performing additional functional assays, the cells were divided into three groups: OSCC-15 cells as the blank control group; OSCC-15 cells, which only expressed the pIRES2-EGFP vector as the negative control (NC) group; and OSCC-15 cells stably expressing the KAI1 gene as the experiment group. All transfection experiments were repeated at least three times.

Western blot analysis. Western blot analysis was performed to measure the protein expression of KAI1. The protein was extracted from the cultured cells by incubation in radioimmunoprecipitation assay buffer (Norgen Biotek Corp., Thorold, ON, Canada) for $30 \mathrm{~min}$ at $37^{\circ} \mathrm{C}$; the lysis buffer contained a protease inhibitor $(2 \mu \mathrm{g} / \mathrm{ml})$, aprotinin $(2 \mu \mathrm{g} / \mathrm{ml})$, leupeptin, $1 \mathrm{M}$ phenylmethylsulfonyl fluoride, $1 \%$ Nonidet P-40, $0.5 \%$ sodium deoxycholate, and $0.1 \%$ sodium dodecyl sulfate (SDS) in 1X PBS. Following lysis, purification of the supernatant was achieved by performing centrifugation at 1,4000 $\mathrm{x} g$ for $5 \mathrm{~min}$ at $4^{\circ} \mathrm{C}$; following which a fixed quantity of protein $(10 \mu \mathrm{l})$ from each sample was suspended in a loading buffer ( $1 \%$ SDS and $1 \%$ dithiothreitol). This suspension was heated to $100^{\circ} \mathrm{C}$ for $5 \mathrm{~min}$ for denaturing of the proteins. The $50 \mu \mathrm{g}(5 \mu \mathrm{g} / \mu \mathrm{l})$ protein samples were then electrophoresed via $10 \%$ SDS polyacrylamide gel electrophoresis, following which the samples were transferred onto a nitrocellulose membrane (cat. no. 88018; Pierce; Thermo Fisher Scientific, Inc.). Following blocking of the membrane with 5\% non-fat dry milk in Tris-Buffered Saline and Tween, containing $10 \mathrm{mmol} / \mathrm{l}$ Tris- $\mathrm{HCl}(\mathrm{pH} 8.0) 100 \mathrm{mmol} / 1 \mathrm{NaCl}$ and $0.05 \%$ Tween, the membrane was incubated overnight at $4^{\circ} \mathrm{C}$ with anti-KAI1 polyclonal antibody (1:200; ab140238; Abcam, Cambridge, UK). Following incubation, the membrane was washed twice with PBS for 5 min and incubated with immunoglobulin G-horseradish peroxidase secondary antibodies $\left(1: 2,000\right.$; ab6789; Abcam) for $2 \mathrm{~h}$ at $4^{\circ} \mathrm{C}$. The expression of glyceraldehyde 3-phosphate dehydrogenase (GAPDH; 1:800; sc-365062; Santa Cruz Biotechnology, Inc., Dallas, TX, USA; or anti-GAPDH; 1;2,000; ab9485; Abcam) was measured in the control group, and each experiment was performed in triplicate. Gel-Pro Analyzer 5.0 (Media Cybernetics, Rockville, MD, USA) was used to analyze the protein expression.

3-(4,5-dimethylthiazol-2-yl)-2,5-diphenyltetrazolium bromide (MTT) assay. The MTT colorimetric assay was used to determine the relative proliferation rate of the tumor cells. The cells $\left(1 \times 10^{4}\right)$ were seeded in 96-well plates and were cultured overnight at $37^{\circ} \mathrm{C}$ in a humidified atmosphere containing $5 \% \mathrm{CO}_{2}$. The following day, $1 \mathrm{X}$ MTT reagent was added to each well; the concentration of this reagent was $5 \mathrm{mg} / \mathrm{ml}$ in a volume of $20 \mu \mathrm{l}$. The cells were incubated for another $4 \mathrm{~h}$, and the absorbance of the cell cultures at $570 \mathrm{~nm}$ were recorded. The experiments were repeated three times. The relative proliferation rate of the cells was calculated using the following equation: Proliferation rate $(\%)=($ experimental absorbance value / control absorbance value) $\times 100 \%$.

Invasion assay. The cell invasion assay was performed in a 96-well Transwell plate with polycarbonate filters $(8-\mu \mathrm{m}$ pore size; EMD Millipore, Billerica, MA, USA). These filters were coated with $50 \mathrm{mg} / \mathrm{l}$ of Matrigel (EMD Millipore), which was previously diluted at a ratio of 1:8 $(3.9 \mu \mathrm{g} / \mu \mathrm{l}, 60-80 \mu \mathrm{l})$ in a serum-free medium. The coated filters were air-dried for $24 \mathrm{~h}$. The transfected OSCC-15 cells $\left(5 \times 10^{4}\right)$ were trypsinized and washed in PBS. The cells were then suspended in $0.1 \%$ serum-containing medium and were loaded into the upper chamber of the filter. The conditioned medium, as a chemoattractant, was added into the lower chamber of the filter. The cells were incubated at $37^{\circ} \mathrm{C}$ in $5 \% \mathrm{CO}_{2}$ for $18 \mathrm{~h}$, following which the cells, which had invaded the lower surface of the filter were fixed with methanol. Subsequently, the cells were washed in PBS and stained with hexamethyl-pararosaniline. The experiment was repeated three times using different cell lines. For quantification, the cells were counted under a light microscope (Olympus Corporation) in five predetermined fields (magnification, x200).

The cell invasion inhibition rate was calculated using the following equation: Cell invasion inhibition rate $=$ (number 
of migrated cells in control group-number of migrated cells in experimental group / number of migrated cells in control group) x100.

Apoptotic assay. At $72 \mathrm{~h}$ post-transfection, the transfected and non-transfected OSCC-15 cells $\left(10^{5}-10^{6}\right.$ for each sample) were trypsinized, collected and washed twice with cold 1X PBS. Each sample was then re-suspended in $100 \mu \mathrm{l}$ of $5 \%$ Annexin V-FITC (ADL, San Diego, CA, USA) reagent. This suspension was incubated at $37^{\circ} \mathrm{C}$ for $15 \mathrm{~min}$ in the dark. Subsequently, $10 \mu \mathrm{l}$ propidium iodide (PI) was added to the suspension, and the cells were incubated for a further $30 \mathrm{~min}$. The apoptotic cells were stained with Annexin V-FITC and analyzed using flow cytometry. The experiments were performed in triplicate.

Tumor xenograft growth. BALB/c nude male mice (5-week-old) were obtained from the Animal Laboratory of the Fourth Military Medical University (Shaanxi, China). The animals were housed in a specific-pathogen-free laboratory $\left(22^{\circ} \mathrm{C}\right.$, natural 12-h light/dark cycle, free access to food/purified water) and were divided into three groups, each containing 21 mice. Non-transfected cells (OSCC-15), cells transfected with the NC plasmid (OSCC-15 + NC), and cells transfected with CD82 (OSCC-15 + CD82) were subcutaneously inoculated into the nude mice. Briefly, on day 1, $100 \mu \mathrm{l}$ cell suspension $\left(1 \times 10^{6}\right.$ cells) was subcutaneously inoculated into the right rear flank of the nude mice. At 7 days post-injection, tumor appearance was detected in these mice. Consequently, the size of the tumors was measured every 3 days using a precision caliper; the measurements were recorded for 25 days. The tumor volume was calculated using the following formula: Volume $(\mathrm{V})=\mathrm{a}$ (length) $\mathrm{xb}^{2}$ (width) $\mathrm{x} 0.52$. At 30 days post-cellular injection, the mice were anesthetized with $4 \%$ hydrous ammonia aldehyde (intraperitoneal injection, $0.01 \mathrm{ml} / \mathrm{g}$ ) sacrificed by cervical dislocation. Subsequently, the tumors were excised and the weights of the tumors were recorded. The tumor inhibitory rate was calculated using the following formula: $\left(\mathrm{V}_{\mathrm{b}}-\mathrm{V}_{\mathrm{a}} / \mathrm{V}_{\mathrm{a}}\right)$ $\mathrm{x} 100 \% . \mathrm{V}_{\mathrm{b}}$ represents the volume of the experiment group; $\mathrm{V}_{\mathrm{a}}$ represents the volume of the control group. The experimental procedure involving these animals was conducted in accordance with the Guide for the Care and Use of Laboratory Animals by the National Institutes of Health (NIH Pub. No. 85-23, revised 1996) (NIH pub. no. 85-23, revised 1996) (25). The experimental study design was approved by the Animal Care and Use Committee of The Fourth Military Medical University.

Statistical analysis. SPSS software version 19.0 (IBM SPSS, Armonk, NY, USA) was used to perform the statistical analysis. The expression of was assessed using the $\chi$-test. The values are presented as the mean \pm standard deviation. $\mathrm{P}<0.05$ was considered to indicate a statistically significant difference.

\section{Results}

Analysis of pIRES2-EGFP-KAII plasmid transfection efficiency. In the $293 \mathrm{~T}$ and OSCC-15 cells transfected with the pIRES2-EGFP-KAI1 plasmid, the overexpression of KAI1/CD82 was analyzed using western blot analysis (Fig. 1A). The data indicated that the expression of KAI1
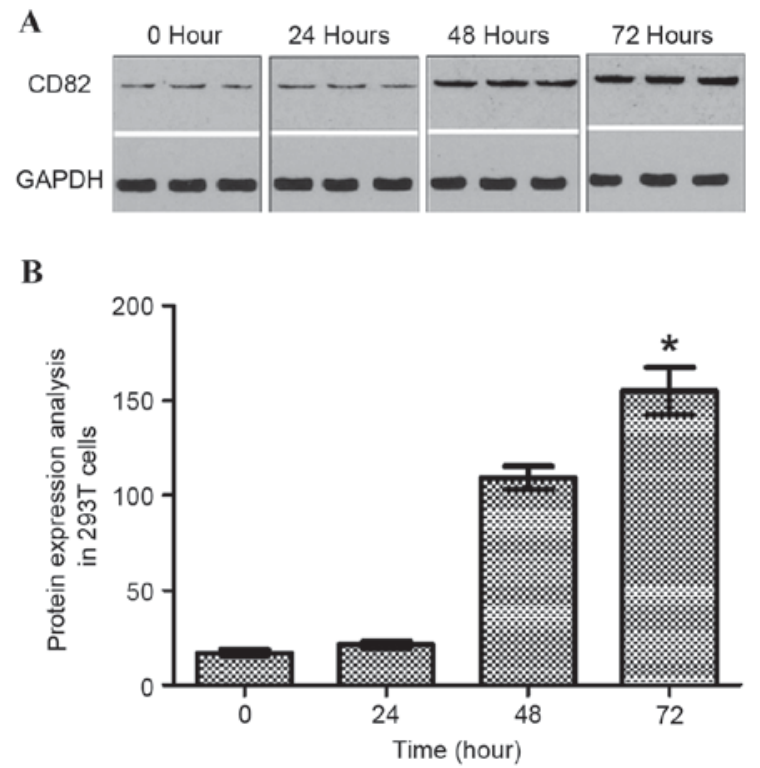

Figure 1. Detection of the protein expression of KAI1/CD82 in transfected 293T cells. (A) Protein levels of KAI1/CD82 were detected using western blot analyses in $293 \mathrm{~T}$ cells at different time points $(0,24,48$ and $72 \mathrm{~h})$ following transfection. (B) Expression of KAI1/CD82 was normalized by the expression of GAPDH. Data are presented as the mean \pm standard deviation $(\mathrm{n}=3) .{ }^{*} \mathrm{P}<0.05$.

increased with increasing duration following transfection of the 293T cells with the pIRES2-EGFP-KAI1 plasmid. At the time point of $72 \mathrm{~h}$, the maximum expression of KAI1 was found. As shown in Fig. 1B, the expression of KAI1/CD82 was normalized with GAPDH. The expression of KAI1 was also verified on the basis of GFP expression, which was determined using fluorescent microscopy following the selection of stable cells from the transfected 293T cells (Fig. 2, above) and OSCC-15 cells (Fig. 2, below). These representative images in the fluorescent fields indicated that the GFP signal was relatively high in $\sim 90 \%$ of the cells.

Effect of the overexpression of KAII/CD82 on cell growth. The present study performed an MTT assay to determine the relative proliferation rate of the three groups of cells (OSCC-15 wild-type; OSCC-15 transfected with the control vector and OSCC-15 transfected with KAI1-expressing vector). The results indicated that the overexpression of KAI1/CD82 in OSCC-15 cells markedly inhibited cell proliferation. The inhibitory effect was most marked $96 \mathrm{~h}$ following plating of the cells (Fig. 3).

Effect of the overexpression of KAII/CD82 on cell invasion. Following $24 \mathrm{~h}$ of culture of cells in the three groups, the number of cells in each group, which migrated through the Transwell polycarbonate membrane, were counted. As shown in Fig. 4A and B, the total number of KAI1/CD82-transfected cells, which migrated was significantly lower, compared with the numbers in the blank and negative control groups $(\mathrm{P}<0.05)$. This data indicated that the overexpression of KAI1/CD82 in OSCC -15 cells was associated with reduced invasive capability.

Effect of the overexpression of KAII/CD82 on cell apoptosis. The present study determined the effect of KAI1/CD82 on apoptosis 


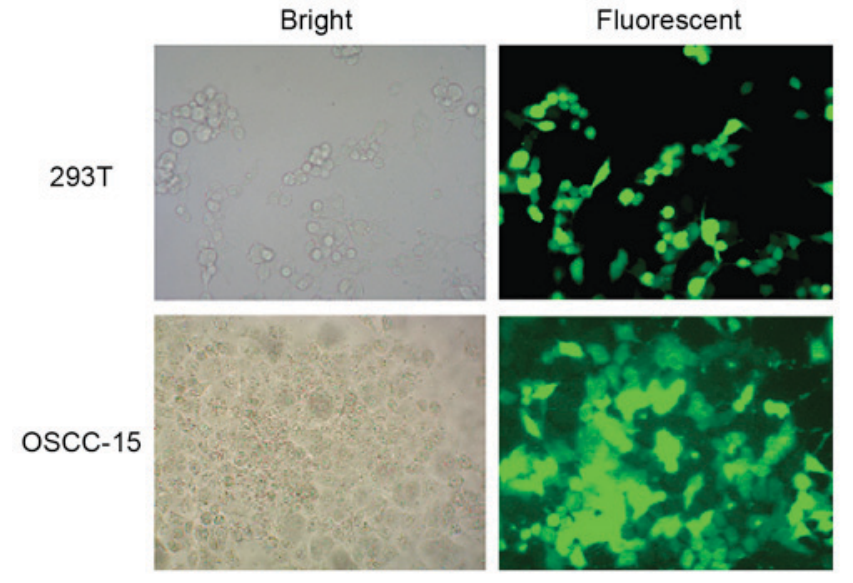

Figure 2. Expression efficiency of KAI/CD82 following stable selection of cells. Expression of GFP indicates the overexpression of KAI1/CD82 in stable cells selected from the transfected 293T cells (top row) and OSCC-15 cells (bottom row). Images were captured at magnification, x10.

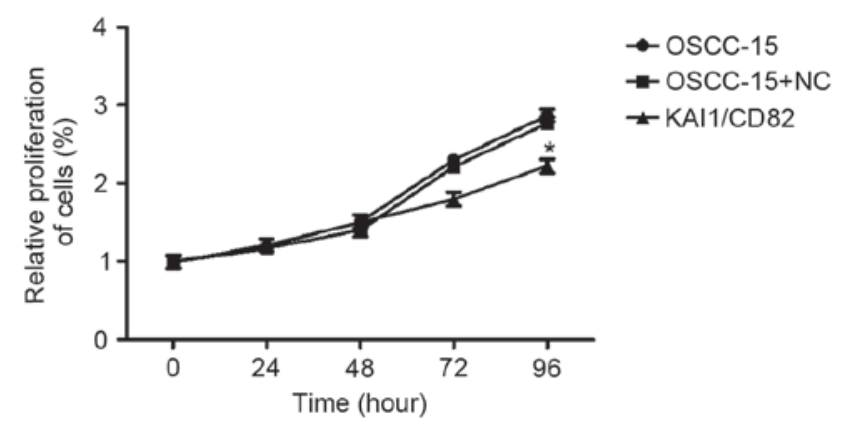

Figure 3. Effect of the overexpression of KAI1 on in vitro proliferation of oral cancer cells. The stably transfected cells were plated, and proliferation rates were determined using a MTT assay. The relative proliferation rate of the experiment group (OSCC-15+ KAI1/CD82) was $2.04 \%$, which was significantly different from those of other groups. Data are presented the mean \pm standard deviation of three different experiments. ${ }^{*} \mathrm{P}<0.05$, vs. OSCC-15 group and negative control group.

by labeling the cells with Annexin-V staining. As shown in Fig. 5A and B, the percentage of Annexin-V-positive staining was significantly higher in the KAI1/CD82-overexpressing cells, compared with the OSCC-15 cells in the blank control or vector control groups. This data indicated that the overexpression of KAI1/CD82 accelerated the apoptosis of OSCC-15 cells.

Effect of the overexpression of KAII/CD82 on xenograft tumor growth. To further determine the effect of the overexpression of KAI1/CD82 on the tumor growth of OSCC-15 cells, the present study used a xenograft tumor model. The KAI1/CD82-overexpressing OSCC-15 cells and negative controls were subcutaneously injected into nude mice, and the tumor volumes were recorded over a period of 1 month. As shown in Fig. 6A, the overexpression of KAI1/CD82 significantly reduced the tumor volumes and weights of the OSCC-15 cells, compared with those of the control vector or blank control groups. Based on the tumor volumes, the tumor inhibitory rate was calculated, which revealed that the overexpression of KAI1/CD82 was associated with the highest tumor inhibitory rate among the three groups (Fig. 6B and C).

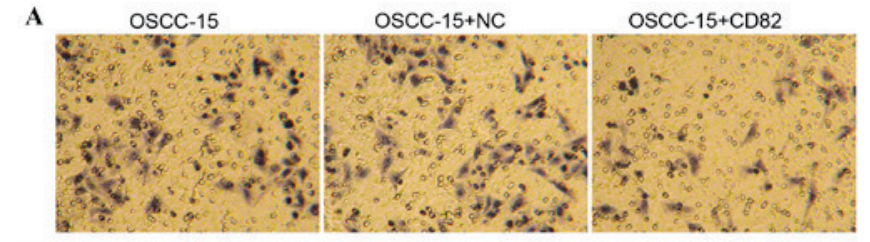

B

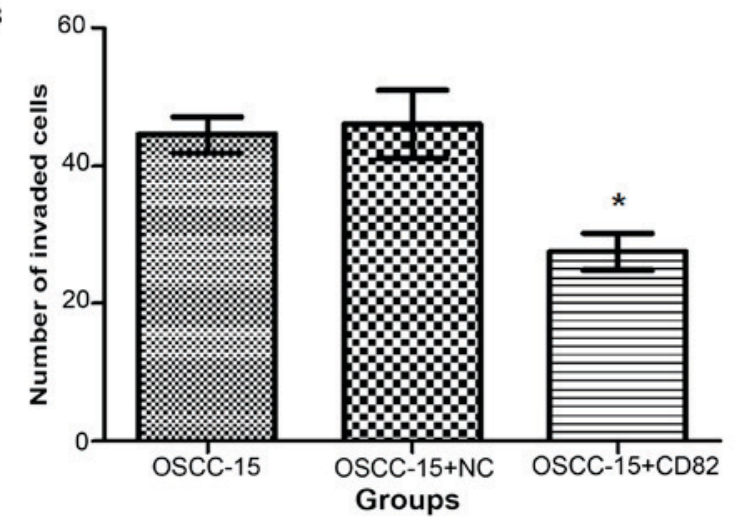

Figure 4. Effect of the expression of KAI1 on the in vitro invasion of OSCC-15 cells. (A) Representative images of the three groups of cells, which invaded through the Matrigel; images were captured under a light microscope (magnification, x200). (B) Quantification of the number of invading cells in each group. Data are presented as the mean \pm standard deviation $(\mathrm{n}=3)$. $^{*} \mathrm{P}<0.05$, vs. OSCC-15 group and negative control group.

These results confirmed that overexpression of KAI1/CD82 had a suppressive effect on the tumorigenicity of oral cancer.

\section{Discussion}

KAI1, also known as CD82, is a member of the TM4SF protein family and has is considered to be a metastatic-suppressor gene (26). In general, TM4SF family proteins are known to be involved in the regulation of cell morphology, cell proliferation, fusion, motility, cell signaling and the immune system (27-29). In particular, KAI1/CD82 has been reported to suppress metastasis in a Dunning rat model of prostatic adenocarcinoma (6). Yang et al (24) reported that the overexpression of KAI1 in breast cancer cells resulted in the suppression of in vitro invasion and in vivo metastasis. KAI1/CD82 interacts with other tetraspanin proteins, integrins and chemokines to regulate the migration, adhesion and signaling of cells $(30)$. Jee et al $(19,31)$ reported that the upregulation of KAI1/CD82 protein is responsible for a significant reduction in the invasion and metastatic potential of non-small cell lung cancer cells. In addition, the overexpression of KAI1/CD82 is associated with the attenuation of integrin signaling. Odintsova et al (32) reported that KAI1/CD82 contributes to epithelial growth factor (EGF)-induced signaling, and described its association with EGF receptor (EGFR) and tetraspanin, which is critical for EGFR desensitization. In the present study, the effect of the overexpression of KAI1 in oral cancer was examined by transfecting KAI1/CD82 cDNA into the OSCC-15 malignant oral cancer cell line. It was found that the overexpression of KAI1/CD82 had an inhibitory effect on in vitro cell growth and invasion. Similarly, a previous study demonstrated that the expression of KAI1/CD82 significantly suppressed the in vitro invasion of breast cells (29). Schoenfeld et al (33) 
A
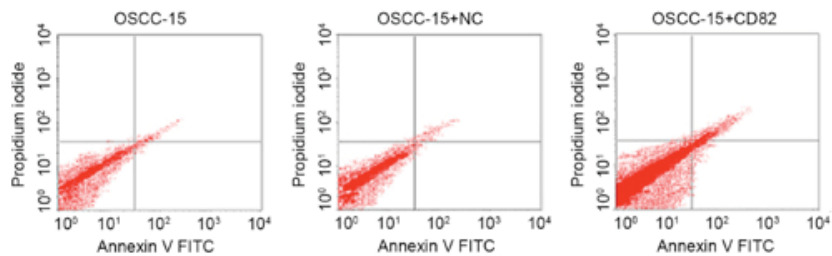

B
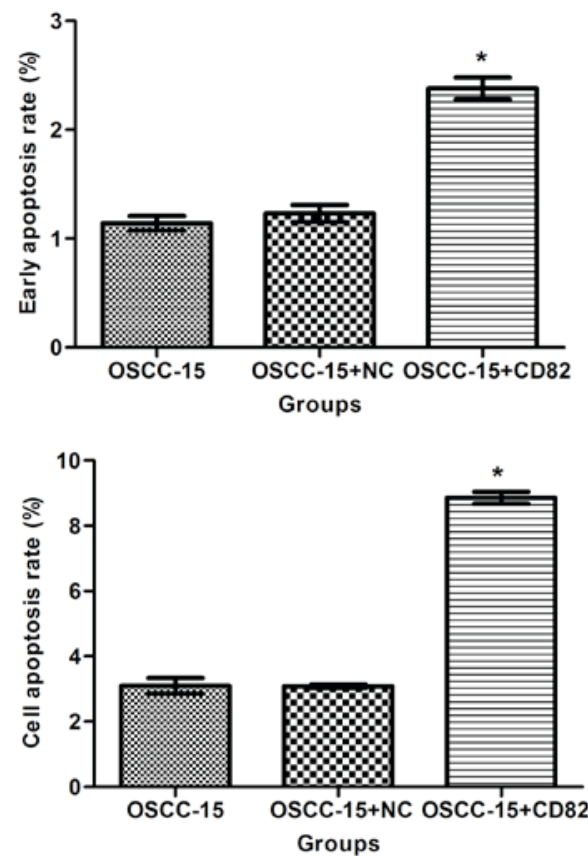

Figure 5. Effect of the expression of KAI/CD82 on apoptosis. The apoptotic rates of OSCC-15, OSCC-15+NC and OSCC-15+KAI1/CD82 cells were determined using Annexin V/PI staining. (A) Flow cytometric analysis; upper right quadrants represent late apoptotic cells; lower right quadrants represent early apoptotic cells. (B) Percentages of early apoptotic cells are shown on the upper graph, total cell apoptosis (late+early apoptosis) in the three groups is shown on the lower graph. Data are presented as the mean \pm standard deviation $(\mathrm{n}=3)$. ${ }^{*} \mathrm{P}<0.05$, vs. OSCC-15 group; ${ }^{*} \mathrm{P}<0.05$, vs. OSCC-15 + NC group.

reported that KAI1/CD82 is also involved in the induction of apoptosis as it produces reactive oxygen intermediates and regulates the pro-apoptotic cdc42-signaling pathway. This is in agreement with the results of the present study study. The data obtained in the present study also indicated that the overexpression of KAI1/CD82 accelerated the apoptosis of OSCC-15 cells.

The xenograft tumor model used in the present study revealed that the overexpression of KAI1/CD82 decreased tumor volumes. Therefore, the overexpression of KAI1/CD82 appeared to have a suppressive effect on the tumorigenicity of oral cancer cells. Although KAI1/CD82 has been extensively investigated for its involvement in the progression of different types of human cancer, how it suppresses the in vivo tumorigenicity of oral cancer cells remains to be fully elucidated. To the best of our knowledge, the present study is the first to clearly demonstrate how the overexpression of $\mathrm{KAI} / \mathrm{CD} 82$ is able to significantly suppress the tumorigenicity of oral cancer cells.

In conclusion, KAI1/CD82 was found to be pivotal in the regulation of oral cancer cells. In relation to the clinical and therapeutic implications of oral cancer, this is an important finding.
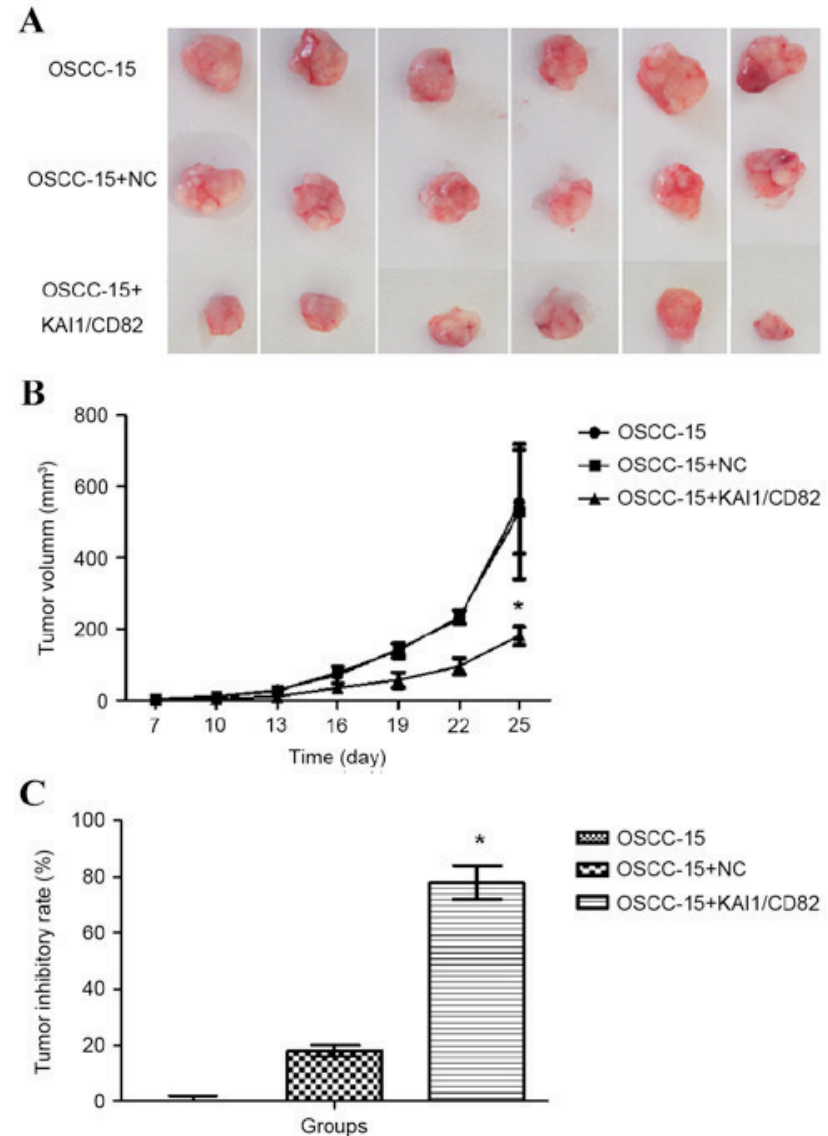

Figure 6. Effect of the overexpression of KAI1 on xenograft tumor growth. The OSCC-15 cells, vector or KAI1/CD82-overexpressing cells were injected into the right rear flank of nude mice. Tumor volumes were recorded for 25 days following inoculation. (A) Tumors excised from three mice in each group. (B) Tumor volumes. $\mathrm{P}<0.05$. (C) Tumor inhibitory rate in the nude mice. $\mathrm{P}<0.05$. Data are presented as the mean \pm standard deviation $(\mathrm{n}=3)$.

\section{Acknowledgements}

This study was supported partially by the National Natural Science Foundation of China (grant no. 81072230), the Project of Scientific and Technological Research Development of Shaanxi Province (grant no. 2014K12-16) and the Scientific Research Starting Foundation for Doctors of Xi'an Medical University (grant no. 2016DOC20).

\section{References}

1. Torre LA, Bray F, Siegel RL, Ferlay J, Lortet-Tieulent J and Jemal A: Global cancer statistics, 2012. CA Cancer J Clin 65: 87-108, 2015.

2. Parkin DM, Bray F, Ferlay J and Pisani P: Global cancer statistics, 2002. CA Cancer J Clin 55: 74-108, 2005.

3. Choudhury JH and Ghosh SK: Promoter hypermethylation profiling identifies subtypes of head and neck cancer with distinct viral, environmental, genetic and survival characteristics. PLoS One 10: e0129808, 2015.

4. Chen C, Mendez E, Houck J, Fan W, Lohavanichbutr P, Doody D, Yueh B, Futran ND, Upton M, Farwell DG, et al: Gene expression profiling identifies genes predictive of oral squamous cell carcinoma. Cancer Epidemiol Biomarkers Prev 17: 2152-2162, 2008.

5. Raudenska M, Sztalmachova M, Gumulec J, Fojtu M, Polanska H, Balvan J, Feith M, Binkova H, Horakova Z, Kostrica R, et al: Prognostic significance of the tumour-adjacent tissue in head and neck cancers. Tumour Biol 36: 9929-9939, 2015. 
6. Dong JT, Lamb PW, Rinker-Schaeffer CW, Vukanovic J, Ichikawa T, Isaacs JT and Barrett JC: KAI1, a metastasis suppressor gene for prostate cancer on human chromosome 11p11.2. Science 268: 884-886, 1995.

7. Vogt AB, Spindeldreher S and Kropshofer H: Clustering of MHC-peptide complexes prior to their engagement in the immunological synapse: Lipid raft and tetraspan microdomains. Immunol Rev 189: 136-151, 2002.

8. Gaugitsch HW, Hofer E, Huber NE, Schnabl E and Baumruker T: A new superfamily of lymphoid and melanoma cell proteins with extensive homology to Schistosoma mansoni antigen Sm23. Eur J Immunol 21: 377-383, 1991.

9. Ichikawa T, Ichikawa Y and Isaacs JT: Genetic factors and suppression of metastatic ability of prostatic cancer. Cancer Res 51: 3788-3792, 1991.

10. Liu W, Iiizumi-Gairani M, Okuda H, Kobayashi A, Watabe M Pai SK, Pandey PR, Xing F, Fukuda K, Modur V, et al: KAI1 gene is engaged in NDRG1 gene-mediated metastasis suppression through the ATF3-NFkappaB complex in human prostate cancer. J Biol Chem 286: 18949-18959, 2011.

11. Park JJ, Jin YB, Lee YJ, Lee JS, Lee YS, Ko YG and Lee M: KAI1 suppresses HIF-1 $\alpha$ and VEGF expression by blocking CDCP1-enhanced Src activation in prostate cancer. BMC Cancer 12: 81, 2012

12. Yu Y, Yang JL, Markovic B, Jackson P, Yardley G, Barrett J and Russell PJ: Loss of KAI1 messenger RNA expression in both high-grade and invasive human bladder cancers. Clin Cancer Res 3: 1045-1049, 1997.

13. You J, Madigan MC, Rowe A, Sajinovic M, Russell PJ and Jackson P: An inverse relationship between KAI1 expression, invasive ability, and MMP-2 expression and activity in bladder cancer cell lines. Urol Oncol 30: 502-508, 2012.

14. Christgen M, Bruchhardt H, Ballmaier M, Krech T, Länger F, Kreipe $\mathrm{H}$ and Lehmann U: KAI1/CD82 is a novel target of estrogen receptor-mediated gene repression and downregulated in primary human breast cancer. Int J Cancer 123: 2239-2246, 2008.

15. Christgen M, Christgen H, Heil C, Krech T, Langer F, Kreipe H and Lehmann U: Expression of KAI1/CD82 in distant metastases from estrogen receptor-negative breast cancer. Cancer Sci 100: $1767-1771,2009$

16. Rowe A and Jackson P: Expression of KITENIN, a KAI1/CD82 binding protein and metastasis enhancer, in bladder cancer cell lines: Relationship to KAI1/CD82 levels and invasive behaviour. Oncol Rep 16: 1267-1272, 2006

17. Hashida H, Takabayashi A, Tokuhara T, Taki T, Kondo K, Kohno N, Yamaoka Y and Miyake M: Integrin alpha3 expression as a prognostic factor in colon cancer: Association with MRP-1/CD9 and KAI1/CD82. Int J Cancer 97: 518-525, 2002.

18. Guo XZ, Friess H, Shao XD, Liu MP, Xia YT, Xu JH and Buchler MW: KAIl gene is differently expressed in papillary and pancreatic cancer: Influence on metastasis. World $\mathrm{J}$ Gastroenterol 6: 866-871, 2000.

19. Jee BK, Park KM, Surendran S, Lee WK, Han CW, Kim YS and Lim Y: KAI1/CD82 suppresses tumor invasion by MMP9 inactivation via TIMP1 up-regulation in the H1299 human lung carcinoma cell line. Biochem Biophys Res Commun 342: $655-661,2006$
20. Takeda T, Hattori N, Tokuhara T, Nishimura Y, Yokoyama M and Miyake M: Adenoviral transduction of MRP-1/CD9 and KAI1/CD82 inhibits lymph node metastasis in orthotopic lung cancer model. Cancer Res 67: 1744-1749, 2007.

21. Uzawa K, Ono K, Suzuki H, Tanaka C, Yakushiji T, Yamamoto N, Yokoe $\mathrm{H}$ and Tanzawa H: High prevalence of decreased expression of KAI1 metastasis suppressor in human oral carcinogenesis. Clin Cancer Res 8: 828-835, 2002.

22. Farhadieh RD, Smee R, Ow K, Yang JL, Russell PJ, Crouch R, Jackson P and Jacobson IV: Down-regulation of KAI1/CD82 protein expression in oral cancer correlates with reduced disease free survival and overall patient survival. Cancer Lett 213: 91-98, 2004.

23. Miyazaki T, Kato H, Kimura H, Inose T, Faried A, Sohda M, Nakajima M, Fukai Y, Masuda N, Manda R, et al: Evaluation of tumor malignancy in esophageal squamous cell carcinoma using different characteristic factors. Anticancer Res 25: 4005-4011, 2005.

24. Yang X, Wei LL, Tang C, Slack R, Mueller S and Lippman ME: Overexpression of KAI1 suppresses in vitro invasiveness and in vivo metastasis in breast cancer cells. Cancer Res 61: 5284-5288, 2001

25. Clark JD, Gebhart GF, Gonder JC, Keeling ME and Kohn DF: Special report: The 1996 guide for the care and use of laboratory animals. ILAR J 38: 41-48, 1997.

26. Liu WM and Zhang XA: KAI1/CD82, a tumor metastasis suppressor. Cancer Lett 240: 183-194, 2006.

27. Skubitz KM, Campbell KD, Iida J and Skubitz AP: CD63 associates with tyrosine kinase activity and CD11/CD18, and transmits an activation signal in neutrophils. J Immunol 157: 3617-3626, 1996.

28. Lagaudrière-Gesbert $C$, Le Naour F, Lebel-Binay S, Billard M, Lemichez E, Boquet P, Boucheix C, Conjeaud H and Rubinstein E: Functional analysis of four tetraspans, CD9, CD53, CD81, and CD82, suggests a common role in costimulation, cell adhesion, and migration: Only CD9 upregulates HB-EGF activity. Cell Immunol 182: 105-112, 1997.

29. Toyo-oka K, Yashiro-Ohtani Y, Park CS, Tai XG, Miyake K, Hamaoka $\mathrm{T}$ and Fujiwara $\mathrm{H}$ : Association of a tetraspanin CD9 with CD5 on the T cell surface: Role of particular transmembrane domains in the association. Int Immunol 11: 2043-2052, 1999.

30. Malik FA, Sanders AJ and Jiang WG: KAI-1/CD82, the molecule and clinical implication in cancer and cancer metastasis. Histol Histopathol 24: 519-530, 2009

31. Jee BK, Lee JY,Lim Y,Lee KH and Jo YH: Effect of KAI1/CD82 on the betal integrin maturation in highly migratory carcinoma cells. Biochem Biophys Res Commun 359: 703-708, 2007.

32. Odintsova E, Sugiura T and Berditchevski F: Attenuation of EGF receptor signaling by a metastasis suppressor, the tetraspanin CD82/KAI-1. Curr Biol 10: 1009-1012, 2000.

33. Schoenfeld N, Bauer MK and Grimm S: The metastasis suppressor gene $\mathrm{C} 33 / \mathrm{CD} 82 / \mathrm{KAI} 1$ induces apoptosis through reactive oxygen intermediates. FASEB J 18: 158-160, 2004. 